\title{
Utility of Red Blood Cell Acetylcholinesterase Measurement in Mechanically Ventilated Subjects After Organophosphate Poisoning
}

\author{
Jeongmi Moon MD and Byeongjo Chun MD
}

\begin{abstract}
BACKGROUND: Many patients with organophosphate poisoning require mechanical ventilation. Muscle acetylcholinesterase ( $\mathrm{AChE}$ ) activity determines the impairment of muscle force generation, and red blood cell (RBC) AChE has been regarded as a surrogate for muscle AChE in organophosphate poisoning. Therefore, this study was conducted to investigate whether RBC AChE at presentation can predict the duration of mechanical ventilatory support and whether RBC AChE at weaning can predict weaning trial outcomes in patients on mechanical ventilation for organophosphate poisoning. METHODS: This retrospective observational case series identified 74 patients with a history of mechanical ventilation secondary to organophosphate poisoning and whose RBC $\mathrm{AChE}$ levels were available at presentation to the emergency department, at $\mathbf{2 4} \mathrm{h}$ of presentation, or at weaning. Data were collected for plasma cholinesterase assay results, weaning outcome, duration of mechanical ventilation, and details of patient management (including ICU stay and amount of atropine and pralidoxime administered). RESULTS: RBC AChE activity levels at presentation and at $24 \mathrm{~h}$ of presentation had a negative correlation with duration of mechanical ventilation in subjects who ingested dimethyl organophosphate, but this correlation was not observed for those who had ingested diethyl or unclassified organophosphate. The optimal cutoff value of $\mathrm{RBC} A \mathrm{ACh}$ activity at presentation for predicting mechanical ventilation for $<7 \mathrm{~d}$ was $1,330 \mathrm{U} / \mathrm{L}$ in subjects intoxicated with dimethyl organophosphate. However, there was no difference in RBC AChE activity at the time of weaning trial between successful and failed weaning events, regardless of the chemical formulation of organophosphate. CONCLUSIONS: We conclude that RBC AChE activity within $24 \mathrm{~h}$ of presentation can help predict the duration of mechanical ventilation for dimethyl organophosphate intoxication; however, RBC AChE activity at the time of weaning trial may not be a suitable parameter for predicting a patient's ability to be weaned from mechanical ventilation. Key words: organophosphates; pesticide; acetylcholinesterase; ventilator weaning. [Respir Care 2014;59(9):1360-1368. (C) 2014 Daedalus Enterprises]
\end{abstract}

\section{Introduction}

The mortality from organophosphate poisoning still remains high, despite numerous investigations over the last

\footnotetext{
The authors are affiliated with the Department of Emergency Medicine, Chonnam National University Medical School, Gwangju, South Korea.

The authors have disclosed no conflicts of interest.

Correspondence: Jeongmi Moon MD, Department of Emergency Medicine, Chonnam National University Medical School, Hak Dong 8, Donggu, Gwangju 501-747, South Korea. E-mail: emdrmjm@gmail.com.
}

DOI: $10.4187 /$ respcare.02916 decades on potential treatment strategies. ${ }^{1,2}$ Although death from organophosphate poisoning is multifactorial, respiratory failure is a significant cause of the high morbidity and mortality rates in the acute setting. ${ }^{3}$ Respiratory failure after organophosphate poisoning results from a combination of paralysis of the respiratory muscles, respiratory center depression, bronchospasm, and abundant secretions. ${ }^{4}$ Up to $86.4 \%$ of patients with symptomatic organophosphate intoxication require mechanical ventilation, and $31.5 \%$ of these patients require ventilation support for $>7$ d. ${ }^{3,5,6}$

Organophosphates interfere with the elimination of acetylcholine by inhibiting acetylcholinesterase (AChE), resulting in accumulation of acetylcholine at nerve termi- 
nals. This in turn causes impairment in neuromuscular signal transmission and muscle force generation in organophosphate poisoning. ${ }^{7,8}$

Because $\mathrm{AChE}$ is encoded by a single gene and because the molecular diversity of this gene is usually confined to the membrane-anchoring tail rather than the catalytic unit, the kinetics of $\mathrm{AChE}$ are thought to be identical in all tissues at all ages. ${ }^{9}$ In addition, kinetic studies have demonstrated that the inhibition and reactivation kinetics of red blood cell (RBC) AChE and muscle AChE are highly comparable in organophosphate poisoning. ${ }^{9}$ Based on these structural and kinetic data, monitoring RBC AChE activity was expected to work as a surrogate assay for muscle AChE activity in patients with organophosphate poisoning. ${ }^{9}$ RBC AChE have been used in many studies to reveal the efficacy of oximes against organophosphate..$^{9,10}$

However, no clinical study has evaluated whether RBC AChE activity can actually be used as a surrogate for muscle AChE activity in patients who require mechanical ventilation secondary to organophosphate poisoning. In mechanically ventilated patients, delays in extubation should be avoided because of the risk for ventilator-associated pneumonia, which significantly increases with each day of mechanical ventilation, and increased cost of care. ${ }^{11}$ It is also critical to assess respiratory muscle force generation, a decisive factor in successful weaning, before a weaning trial because failed weaning is associated with pneumonia, prolonged hospital and ICU stays, and even increased mortality. ${ }^{12}$

The aims of this study were to investigate whether the initial RBC AChE assay can help predict duration of mechanical ventilation and whether RBC AChE assay at weaning can predict outcomes of weaning organophosphatepoisoned patients from mechanical ventilation.

\section{Methods}

\section{Study Design}

This was a single-institution retrospective cohort study performed by chart review. The study design was approved by the institutional review board at Chonnam National University Hospital (Gwangju, South Korea).

\section{Subjects}

The inclusion criteria were: any subject 18 y or older who required mechanical ventilation secondary to organophosphate ingestion and underwent a weaning trial between 2004 and 2013. To be included in the study, each subject was required to have had RBC AChE activity measured at presentation to the emergency department, $24 \mathrm{~h}$ after presentation, or within $12 \mathrm{~h}$ before or after weaning from mechanical ventilation. The review identified 76 sub-

\section{QUICK LOOK}

\section{Current knowledge}

Organophosphate poisoning most commonly results from exposure to insecticides or nerve agents. The mortality is high; $90 \%$ of patients require mechanical ventilation due to muscle paralysis, bronchospasm, excessive secretions, bronchospasm, and respiratory depression. Red blood cell acetylcholinesterase (AChE) is considered a surrogate for muscle $\mathrm{AChE}$ following organophosphate poisoning.

\section{What this paper contributes to our knowledge}

RBC AChE activity within $24 \mathrm{~h}$ of presentation can help predict the duration of mechanical ventilation following organophosphate poisoning. The presence of RBC AChE cannot be used as a predictor of weaning success.

jects. The diagnosis of organophosphate poisoning had been based on the following criteria: a history of organophosphate ingestion provided by subject or a witness, clinical manifestations consistent with organophosphate poisoning, decreased plasma cholinesterase activity, and improvement of signs and symptoms after treatment with atropine and pralidoxime.

The exclusion criteria were: history of other pre-existing comorbid conditions $(n=1)$ and history of lung disease $(n=1)$. After exclusion, the data from the remaining 74 subjects were included in the analysis.

Progressive inhibition of $\mathrm{AChE}$ results from phosphorylation of the active-site serine. The inhibited AChE undergoes a nonenzymatic dealkylation reaction in the bound organophosphate moiety, leading to the aging process, which is an irreversible conformational change in $\mathrm{AChE}$ that renders it inactive.

The chemical structure of organophosphate is a decisive parameter in the rate of spontaneous reactivation of inhibited $\mathrm{AChE}$ and the rate of aging of human AChE; the half-life of the aging process of AChE by dimethyl organophosphate is $3.7 \mathrm{~h}$, whereas that of AChE by diethyl organophosphate is $33 \mathrm{~h} .{ }^{13,14}$ To evaluate whether the RBC AChE activity level within the first $24 \mathrm{~h}$ after presentation to an emergency department can predict the duration of mechanical ventilation, we divided the subjects into 3 groups according to the chemical formulation of organophosphate: dimethyl group, diethyl group, and unclassified organophosphate group for a subset of subjects whose ingested organophosphate did not match either the dimethoxyl or diethyl classification.

Once the aging process has completed (several days after organophosphate ingestion), the AChE enzyme can- 
not be reactivated by oxime treatment, regardless of the chemical formula of the organophosphate. ${ }^{15}$ Therefore, we did not divide the subjects whose RBC AChE activity levels were measured at weaning into the 3 groups.

Each subject in the study had received general supportive measures. These included decontamination, mechanical ventilation support, and administration of atropine and pralidoxime in the ICU. Atropine was given either as a continuous infusion or as a bolus injection every $15 \mathrm{~min}$ and was titrated to achieve adequate atropinization, including dry bronchial secretions. Pralidoxime was administered at up to $0.5-1.0 \mathrm{~g} / \mathrm{h}$ as long as reactivation could be anticipated according to the severity of clinical conditions and the time course of plasma cholinesterase activity. The need for intubation and mechanical ventilation support was estimated by the emergency physician on call. This decision was based on decreased mental status, low $\mathrm{P}_{\mathrm{aO}} / \mathrm{F}_{\mathrm{IO}_{2}}$, hemodynamic instability, or respiratory acidosis. Subjects underwent mechanical ventilator weaning trials if they satisfied the criteria for weaning, which included improvement of the conditions that prompted mechanical ventilation, discontinuation of sedatives and neuromuscular blockers, absence of fever, hemodynamic stability, $\mathrm{P}_{\mathrm{aO}_{2}} / \mathrm{F}_{\mathrm{IO}_{2}}>200, \mathrm{~F}_{\mathrm{IO}_{2}} \leq 0.4$, PEEP $\leq 5 \mathrm{~cm} \mathrm{H} \mathrm{O}$, breathing frequency/tidal volume $<105$, and breathing frequency $<35$ breaths/min. Subjects were observed after weaning and extubation and were re-intubated and ventilated for the following signs or symptoms: breathing frequency $>35$ breaths/min, arterial oxygen saturation $<90 \%$, heart rate $>140$ beats $/ \mathrm{min}$, or sustained increase or decrease in heart rate $>20 \%$, systolic blood pressure $>180$ or $<90$ $\mathrm{mm} \mathrm{Hg}$, neurological disorientation, diaphoresis, or thoracoabdominal asynchrony.

The blood samples for RBC AChE assay had been collected with ethylenediaminetetraacetic acid, and the activity was measured by photometric test (Roche, Seoul, South Korea). This test was based on the reaction that RBC AChE splits acetylcholine into acetate and thiocholine, the latter of which reacts with dithiobisnitrobenzoic acid to form yellow 5-mercapto-2-nitrobenzoic acid. The RBC AChE activity was calculated in reference to the respective hematocrit level and plasma and whole blood cholinesterase activities. The normal range of RBC AChE activity was 11,188-16,698 U/L. An electrophysiology study has demonstrated normal neuromuscular transmission at $>30 \%$ of normal RBC AChE levels and strong impairment of neuromuscular transmission at levels $<10 \%{ }^{8,16}$ Thus, we considered activity levels of 3,000 and 1,000 U/L RBC AChE as 30 and $10 \%$ of normal physiologic activity, respectively.

\section{Data Collection and Analysis}

The medical records were reviewed, and the following data were collected: age, gender, cause of exposure, type of organophosphate ingested, laboratory results (including serial $\mathrm{RBC}$ AChE activities), atropine and pralidoxime administered during hospitalization, time interval from ingestion to arrival at our hospital, time interval from arrival to mechanical ventilation support, duration of mechanical ventilation, $\mathrm{P}_{\mathrm{aO}} / \mathrm{F}_{\mathrm{IO}}$, breathing frequency, mental state at weaning, total amount of administered atropine and pralidoxime up to the weaning trial, outcomes of weaning trials, time interval from failed weaning to re-intubation, ICU stay, and survival outcome. The amounts of ingested organophosphate were estimated as a spoonful $(5 \mathrm{~mL})$, mouthful $(25 \mathrm{~mL})$, cup $(100 \mathrm{~mL})$, and bottle $(300 \mathrm{~mL}) \cdot{ }^{17} \mathrm{~A}$ weaning trial was considered successful if the subject remained extubated for $72 \mathrm{~h} .{ }^{18}$ In all subjects, each weaning trial was considered to be a new episode.

The baseline subject characteristics are presented as frequency for categorical variables or as median and interquartile range or mean $\pm \mathrm{SD}$ for continuous variables. The Mann-Whitney test or $t$ test was performed for analysis of continuous variables according to normality. Normality of continuous variables was tested using the Shapiro-Wilk test. The Fisher exact test or the chi-square test was performed to compare categorical variables.

Correlations between RBC AChE activities within the first $24 \mathrm{~h}$ after presentation and the duration of mechanical ventilation were determined using the Pearson rank method or Spearman's rank method. The receiver operating characteristic curve was used to obtain the area under the curve with $95 \% \mathrm{CI}$, as well as the sensitivity and specificity of RBC AChE for predicting subjects who required mechanical ventilation for $<7 \mathrm{~d} .{ }^{19}$ The Youden index (sensitivity + specificity -1 ) was obtained, and the RBC AChE activity with maximal Youden index was selected as the optimal cutoff value. Serial RBC AChE activity across time was analyzed using the Friedman test. $P$ values $<.05$ were considered to be statistically significant. All statistical analyses were performed using SPSS 21.0 (SPSS, Chicago, Illinois).

\section{Results}

\section{Subjects}

Of 204 patients who presented to our emergency department after organophosphate ingestion, 94 (46.1\%) underwent mechanical ventilation (Fig. 1). Of these 94 patients, 82 underwent a weaning trial at our hospital, and 12 either died or were transferred to another institution before weaning trials. Of these 82 patients, 10 had RBC AChE activities measured both at presentation and at $24 \mathrm{~h}$ of presentation, and 20 had RBC AChE activities measured at both presentation and weaning. Additionally, 44 patients had RBC AChE activities measured at presentation, at $24 \mathrm{~h}$ of presentation, and at weaning. 


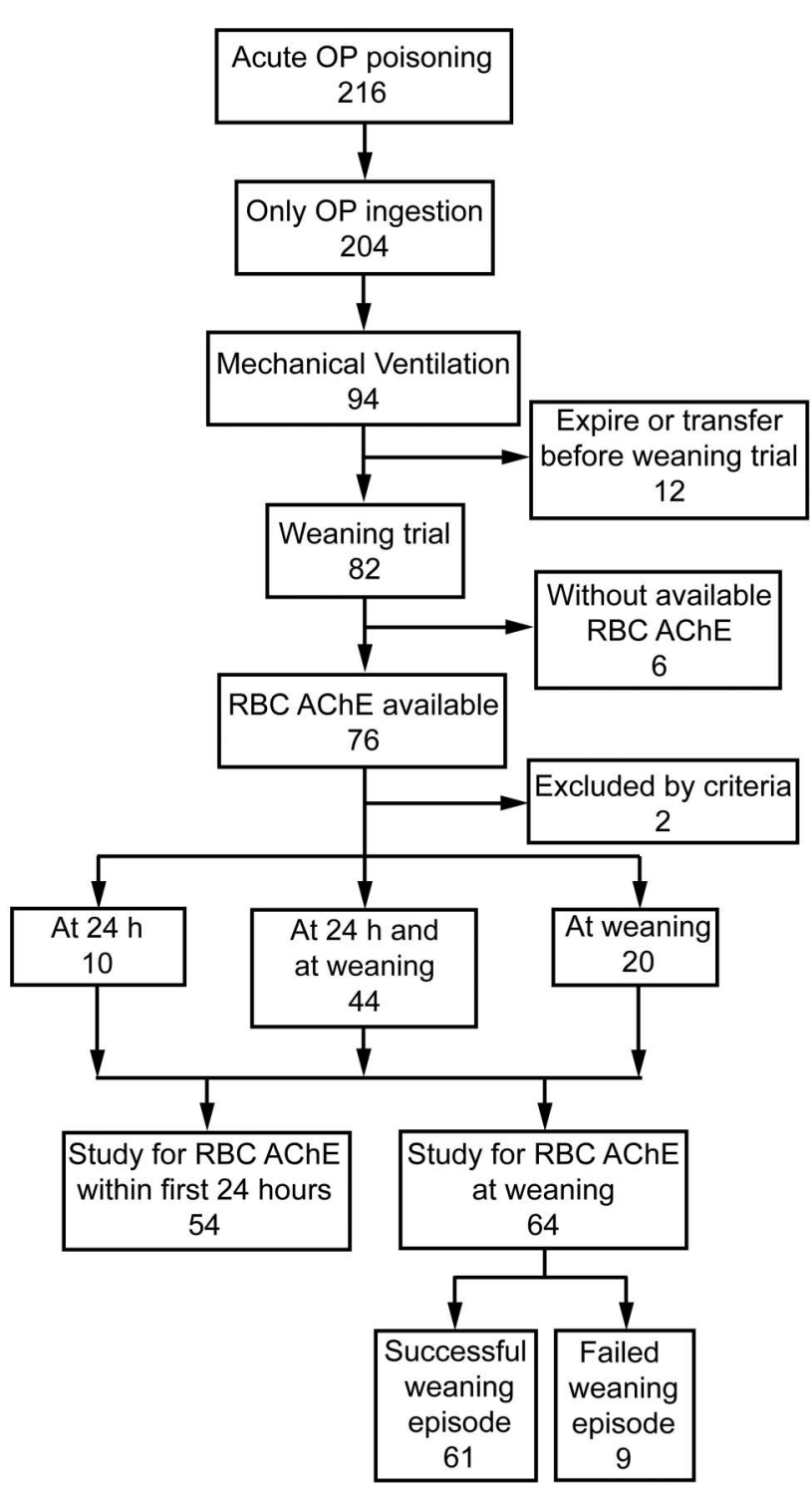

Fig. 1. Study flow chart. OP = organophosphate; $\mathrm{RBC} A \mathrm{AChE}=$ red blood cell acetylcholinesterase.

Finally, data for 54 subjects with RBC AChE activities measured both at presentation and at $24 \mathrm{~h}$ of presentation were used in the analysis of the relationship between initial RBC AChE activity and duration of mechanical ventilation. The data for 64 subjects who had RBC AChE activities measured at weaning were used for studying whether the RBC AChE activity at weaning predicts the outcome of weaning from mechanical ventilation.

\section{RBC AChE Activity Within the First 24 h After Intoxication}

The baseline characteristics and clinical course of the 54 subjects who had RBC AChE activities measured both at
Table 1. Characteristics of Subjects With RBC AChE Activities Measured at Admission and at $24 \mathrm{~h}$ After Admission

\begin{tabular}{|c|c|}
\hline Variable & Values $(n=54)$ \\
\hline Age, mean $\pm \mathrm{SD}, \mathrm{y}$ & $58.3 \pm 2.0$ \\
\hline Male, $n(\%)$ & $36(66.7)$ \\
\hline \multicolumn{2}{|l|}{ Ingestion intent, $n(\%)$} \\
\hline Intentional & $33(61.1)$ \\
\hline Unknown & $20(37.0)$ \\
\hline \multicolumn{2}{|l|}{ Type of organophosphate ingested, $n(\%)$} \\
\hline Dimethyl organophosphate & $37(68.5)$ \\
\hline Diethyl organophosphate & $6(11.1)$ \\
\hline Unclassified organophosphate & $11(20.4)$ \\
\hline $\begin{array}{l}\text { Time from ingestion to admission, } \\
\text { median (IQR), } \mathrm{h}\end{array}$ & $2.8(1.6-5.0)$ \\
\hline Ingested amount, median (IQR), mL & $200.0(100.0-300.0)$ \\
\hline $\begin{array}{l}\text { Systolic blood pressure, median (IQR), } \\
\text { mm Hg }\end{array}$ & $130.0(110.0-150.0)$ \\
\hline Altered mental state, $n(\%)$ & $54(100)$ \\
\hline $\mathrm{pH}$, median $(\mathrm{IQR})$ & $7.37(7.29-7.41)$ \\
\hline $\mathrm{HCO}_{3}^{-}$, mean $\pm \mathrm{SD}, \mathrm{mmol} / \mathrm{L}$ & $18.7 \pm 0.6$ \\
\hline Base excess, mean $\pm \mathrm{SD}, \mathrm{mmol} / \mathrm{L}$ & $-6.6 \pm 0.8$ \\
\hline Hemoglobin, mean $\pm \mathrm{SD}, \mathrm{g} / \mathrm{dL}$ & $14.5 \pm 0.3$ \\
\hline Lactate, mean $\pm \mathrm{SD}, \mathrm{mmol} / \mathrm{L}$ & $4.6 \pm 0.4$ \\
\hline Creatine kinase, median (IQR), U/L & $142.0(86.0-255.0)$ \\
\hline Creatine kinase MB, median (IQR), IU/L & $13.6(7.1-32.8)$ \\
\hline Corrected QT interval, mean $\pm \mathrm{SD}$, ms & $462.9 \pm 6.5$ \\
\hline \multicolumn{2}{|l|}{ Plasma cholinesterase, median (IQR), U/L } \\
\hline At admission & $769.0(204.8-1,748.5)$ \\
\hline At $24 \mathrm{~h}$ after admission & $722.0(228.8-2,060.3)$ \\
\hline At $48 \mathrm{~h}$ after admission* & $1,107.0(320.8-2,276.0)$ \\
\hline \multicolumn{2}{|l|}{ RBC AChE, median (IQR), U/L } \\
\hline At admission & $3,274.0(9,31.0-8,408.5)$ \\
\hline At $24 \mathrm{~h}$ after admission & $3,781.0(1,216.5-9,103.3)$ \\
\hline At $48 \mathrm{~h}$ after admission* & $3,843.0(1,075.0-8,862.0)$ \\
\hline $\begin{array}{c}\text { Amount of administered atropine during } \\
\text { hospitalization, median (IQR), mg }\end{array}$ & $532.5(254.3-1,078.8)$ \\
\hline $\begin{array}{l}\text { Amount of administered pralidoxime } \\
\text { during hospitalization, median (IQR), g }\end{array}$ & $62.0(37.0-122.0)$ \\
\hline $\begin{array}{l}\text { Duration of mechanical ventilation, } \\
\text { median (IQR), d }\end{array}$ & $8.0(5.5-15.5)$ \\
\hline ICU stay, median (IQR), d & $11.5(7.0-21.5)$ \\
\hline Hospitalization stay, median (IQR), d & $19.0(12.0-27.3)$ \\
\hline
\end{tabular}

Data are presented as $n(\%)$ or mean \pm SD for normally distributed continuous variables or as median with interquartile range (IQR) for non-normally distributed continuous variables. * Plasma cholinesterase and red blood cell acetylcholinesterase (RBC AChE) levels at $48 \mathrm{~h}$ after admission were available for 31 subjects.

presentation and at $24 \mathrm{~h}$ of presentation are summarized in Table 1. These subjects presented at a median of $2.8 \mathrm{~h}$ after poisoning, with a median estimated organophosphate ingestion volume of $200 \mathrm{~mL}$. The inhibited mean of 769.0 U/L plasma cholinesterase activity (normal range 5,320 $12,920 \mathrm{U} / \mathrm{L}$ ) at presentation was definite evidence of organophosphate poisoning. The common organophosphate compounds were fenitrothion $(n=12)$, ethyl p-nitrophenol thiobenzene phosphonate $(n=9)$, dichlorvos $(n=7)$, 
Table 2. Correlation Between RBC AChE Acetylcholinesterase Activities at $24 \mathrm{~h}$ After Admission and Duration of Mechanical Ventilation

\begin{tabular}{|c|c|c|c|c|c|c|}
\hline \multirow{3}{*}{ RBC AChE activity } & \multicolumn{6}{|c|}{ Duration of Mechanical Ventilation } \\
\hline & \multicolumn{2}{|c|}{$\begin{array}{l}\text { Dimethyl OP } \\
\quad(n=37)\end{array}$} & \multicolumn{2}{|c|}{$\begin{array}{l}\text { Diethyl OP } \\
\quad(n=6)\end{array}$} & \multicolumn{2}{|c|}{$\begin{array}{l}\text { Unclassified OP } \\
\quad(n=11)\end{array}$} \\
\hline & $\mathrm{r}$ & $P$ & $\mathrm{r}$ & $P$ & $\mathrm{r}$ & $P$ \\
\hline At admission & -0.42 & .01 & 0.03 & .95 & -0.20 & .59 \\
\hline $\begin{array}{c}\text { At } 24 \mathrm{~h} \text { after } \\
\text { admission }\end{array}$ & -0.42 & .01 & 0.07 & .89 & -0.51 & .11 \\
\hline
\end{tabular}

and methidathion $(n=7)$. When subjects were categorized according to chemical structure of ingested organophosphate, 37 (68.5\%) subjects ingested dimethyl organophosphate, and $6(11.1 \%)$ ingested diethyl organophosphate. Eleven (20.4\%) subjects were poisoned with unclassified organophosphate. Mechanical ventilation was initiated at a median of $4 \mathrm{~h}$ after organophosphate ingestion, and 32 (59.3\%) subjects required mechanical ventilatory support for $>7 \mathrm{~d}$.

When investigating the relationship between duration of mechanical ventilation and RBC AChE activity levels within the first $24 \mathrm{~h}$ after presentation according to chemical structure of organophosphate ingested, RBC AChE activities had a significant negative correlation with duration of mechanical ventilation in subjects exposed to dimethyl organophosphate (Table 2). However, no such correlation was observed for the diethyl and unclassified groups.

Among the 37 subjects intoxicated with dimethyl organophosphate, 15 (40.5\%) needed mechanical ventilatory support for $<7 \mathrm{~d}$. In predicting duration of mechanical ventilation for $<7 \mathrm{~d}$, receiver operating characteristic curve analysis demonstrated that RBC AChE activity at presentation had a higher predictive performance with an area under the curve of 0.812 (95\% CI 0.67-0.96) than RBC $\mathrm{AChE}$ activity at $24 \mathrm{~h}$ after presentation. The optimum cutoff value for prediction of RBC AChE activity at presentation was $1,330 \mathrm{U} / \mathrm{L}$, with sensitivity and specificity of 93.3 and $63.6 \%$, respectively (Table 3 ).

\section{Activity of RBC AChE at Weaning}

Table 4 provides the baseline characteristics and clinical course of 64 subjects with RBC AChE activity measured at weaning. Weaning trials took place at $11.5 \pm 1.1 \mathrm{~d}$ after organophosphate ingestion for these 64 subjects. Sixty-one episodes of successful weaning and 9 episodes of failed weaning had occurred. In 9 episodes of failed weaning,
Table 3. Cutoff Values for RBC AChE Activity at 24 h After Admission to Predict Duration of Mechanical Ventilation for $<7 \mathrm{~d}$

\begin{tabular}{|c|c|c|c|c|c|}
\hline $\begin{array}{c}\text { RBC AChE } \\
\text { Activity }\end{array}$ & AUC & $95 \% \mathrm{CI}$ & $\begin{array}{c}\text { Cutoff } \\
(\mathrm{U} / \mathrm{L})\end{array}$ & $\begin{array}{c}\text { Sensitivity } \\
(\%)\end{array}$ & $\begin{array}{c}\text { Specificity } \\
(\%)\end{array}$ \\
\hline At admission & 0.81 & $0.67-0.96$ & 1,330 & 93.3 & 63.6 \\
\hline $\begin{array}{c}\text { At } 24 \mathrm{~h} \text { after } \\
\text { admission }\end{array}$ & 0.75 & $0.58-0.93$ & 3,480 & 78.6 & 71.4 \\
\hline \multicolumn{6}{|c|}{$\begin{array}{l}\mathrm{AUC}=\text { area under the curve } \\
\mathrm{RBC} \mathrm{AChE}=\text { red blood cell acetylcholinesterase }\end{array}$} \\
\hline
\end{tabular}

subjects were re-intubated at a mean of $17.2 \mathrm{~h}$ after extubation, and the subjects were successfully weaned from mechanical ventilation at a median of $120.0 \mathrm{~h}$ after the previous weaning trial.

At weaning trials, the systolic blood pressure, $\mathrm{P}_{\mathrm{aO}} / \mathrm{F}_{\mathrm{IO}}$, breathing frequency, Glasgow coma score, and total amount of administered atropine and pralidoxime up to weaning trials were not different between successful and failed weaning episodes (Table 5). There were no differences in RBC AChE activity at the time of weaning trial between 61 episodes of successful weaning and 9 episodes of failed weaning. The increases in RBC AChE activity levels from admission to time of weaning trial did not differ between the 2 groups.

When RBC AChE activity levels were categorized using 3,000 U/L ( $\sim 30 \%$ of normal) or 1,000 U/L $(\sim 10 \%$ of normal) as the cutoff point, $\mathrm{RBC}$ AChE levels were $<1,000$ $\mathrm{U} / \mathrm{L}$ in $11(18.0 \%)$ of the 61 successful weaning episodes (Table 6). In contrast, RBC AChE levels were $>3,000$ $\mathrm{U} / \mathrm{L}$ in $4(44.4 \%)$ of the 9 failed weaning episodes.

RBC AChE activity levels were measured at presentation for 5 of the 9 failed weaning episodes and then following a successful weaning episode, but there were no significant differences in RBC AChE activity levels across time (Fig. 2). A 35-y-old female subject whose RBC AChE level at admission was 6,538 U/L experienced failed weaning with an RBC AChE level of 1,825 U/L at $8 \mathrm{~d}$, and this subject was successfully weaned from mechanical ventilation with an RBC AChE level of $614 \mathrm{U} / \mathrm{L}$ at $14 \mathrm{~d}$.

\section{Discussion}

\section{Subjects}

Considering the high incidence of respiratory failure in organophosphate poisoning, proper ventilatory management and antidote administration are critical in reducing mortality and morbidity. At our institution, the incidence of mechanical ventilation secondary to organophosphate ingestion was $46.1 \%$, and $43(58.1 \%)$ of the total 74 subjects needed mechanical ventilation for $>7 \mathrm{~d}$. Even with 
Table 4. Characteristics of Subjects With RBC AChE Activities at Weaning

\begin{tabular}{|c|c|}
\hline Variable & Values $(n=64)$ \\
\hline Age, mean $\pm S D, y$ & $58.3 \pm 1.8$ \\
\hline Male, $n(\%)$ & $47(73.4)$ \\
\hline \multicolumn{2}{|l|}{ Ingestion intent, $n(\%)$} \\
\hline Intentional & $34(53.1)$ \\
\hline Unknown & $27(42.2)$ \\
\hline \multicolumn{2}{|l|}{ Type of organophosphate ingested, $n(\%)$} \\
\hline Dimethyl organophosphate & $40(62.5)$ \\
\hline Diethyl organophosphate & $8(12.5)$ \\
\hline Unclassified organophosphate & $16(25.0)$ \\
\hline $\begin{array}{l}\text { Time from ingestion to admission, } \\
\text { median (IQR), h }\end{array}$ & $3.0(2.0-5.0)$ \\
\hline Ingested amount, median (IQR), mL & $100.0(50.0-262.5)$ \\
\hline $\begin{array}{l}\text { Systolic blood pressure, median (IQR), } \\
\mathrm{mm} \mathrm{Hg}\end{array}$ & $130.0(118.5-150.0)$ \\
\hline Altered mental state, $n(\%)$ & $64(100)$ \\
\hline $\mathrm{pH}$, median (IQR) & $7.39(7.29-7.42)$ \\
\hline $\mathrm{HCO}_{3}^{-}$, median (IQR), $\mathrm{mmol} / \mathrm{L}$ & $19.0(16.1-21.7)$ \\
\hline Base excess, median (IQR), mmol/L & $-5.3(-9.3$ to -2.1$)$ \\
\hline Hemoglobin, mean $\pm \mathrm{SD}, \mathrm{g} / \mathrm{dL}$ & $14.7 \pm 0.2$ \\
\hline Lactate, mean $\pm \mathrm{SD}, \mathrm{mmol} / \mathrm{L}$ & $4.7 \pm 0.4$ \\
\hline Corrected QT interval, mean $\pm \mathrm{SD}, \mathrm{ms}$ & $465.7 \pm 6.6$ \\
\hline \multicolumn{2}{|l|}{ Plasma cholinesterase, median (IQR), U/L } \\
\hline At admission & $670.0(248.8-1,766.5)$ \\
\hline At $24 \mathrm{~h}$ after admission* & $897.0(234.0-2,237.0)$ \\
\hline At weaning & 2,014.0 (748.8-2,928.5) \\
\hline \multicolumn{2}{|l|}{ RBC AChE, median (IQR), U/L } \\
\hline At admission & $3,961.0(1,046.3-9,135.0)$ \\
\hline At $24 \mathrm{~h}$ after admission* & $3,721.0(1,216.0-9,103.3)$ \\
\hline At weaning & $3,424.5(1,441.0-8,761.0)$ \\
\hline $\begin{array}{l}\text { Amount of administered atropine during } \\
\text { hospitalization, median (IQR), mg }\end{array}$ & $480.8(262.8-1,046.3)$ \\
\hline $\begin{array}{l}\text { Amount of administered pralidoxime during } \\
\text { hospitalization, median (IQR), g }\end{array}$ & $50.0(37.0-113.0)$ \\
\hline $\begin{array}{l}\text { Duration of mechanical ventilation, } \\
\text { median (IQR), d }\end{array}$ & $8.0(5.0-14.3)$ \\
\hline ICU stay, median (IQR), d & $10.5(7.0-21.8)$ \\
\hline Hospitalization stay, median (IQR), d & $17.0(11.3-28.0)$ \\
\hline \multicolumn{2}{|c|}{$\begin{array}{l}\text { Data are presented as } n(\%) \text { or mean } \pm \text { SD for normally distributed continuous variables or } \\
\text { as median with interquartile range (IQR) for non-normally distributed continuous variables. } \\
* \text { Plasma cholinesterase and red blood cell acetylcholinesterase (RBC AChE) levels at } 48 \mathrm{~h} \\
\text { after admission were available in } 44 \text { subjects. }\end{array}$} \\
\hline
\end{tabular}

weaning trials based on common criteria, $12.8 \%$ of the 70 weaning episodes failed. This rate of failure to wean is higher than the $6 \%$ reported for mechanical ventilation secondary to trauma. ${ }^{20}$ Here, we investigate whether RBC AChE activity within the first $24 \mathrm{~h}$ after presentation can identify patients who require longer periods of ventilation and whether the RBC AChE level at weaning can differentiate which patient is ready to be weaned from a mechanical ventilator. To the best of our knowledge, this is the first study to clinically evaluate the utility of RBC
$\mathrm{AChE}$ measurement in patients requiring mechanical ventilation after organophosphate poisoning.

\section{RBC AChE Within the First $24 \mathrm{~h}$ After Intoxication}

Predicting the duration of mechanical ventilation helps physicians to avoid unnecessary delays in extubation and to plan for tracheostomy time in patients who need prolonged mechanical ventilation. Because of markedly different time courses of AChE inhibition according to chemical properties of specific organophosphate (such as water solubility; presence of dimethyl, diethyl, or S-alkyl compounds; or biotransformation to active metabolites), we classified subjects according to the type of organophosphate ingested. We found that decreased RBC AChE levels within the first $24 \mathrm{~h}$ after presentation correlated with prolonged mechanical ventilation after dimethyl organophosphate intoxication. This finding is similar to the results from a previous study by Thiermann et $a 1,{ }^{8}$ who suggested that RBC AChE activity appears to be a suitable surrogate parameter of synaptic AChE activity during the first day of dimethyl or diethyl organophosphate intoxication. RBC AChE activity at $24 \mathrm{~h}$ had a significant correlation with 96-h mortality in shrimp exposed to dimethyl organophosphate (malathion, azinphosmethyl) or diethyl organophosphate (chlorpyrifos). ${ }^{21}$ In contrast to findings from those studies, RBC AChE activity was not related to the duration of mechanical ventilation after diethyl organophosphate intoxication in our study. This lack of correlation may be explained by inadequate sample size for subjects exposed to diethyl organophosphate. At $24 \mathrm{~h}$ after exposure, the dimethyl organophosphate-bound RBC AChE had completely aged, in contrast to RBC AChE bound to diethyl organophosphate, $<50 \%$ of which would have been aged. ${ }^{13,14}$ Perhaps this difference partially contributed to the lack of correlation.

Additionally, we found the cutoff level of 1,330 U/L for RBC AChE activity at presentation to have $93.3 \%$ sensitivity and $63.6 \%$ specificity for predicting mechanical ventilation of $<7 \mathrm{~d}$ in subjects intoxicated with dimethyl organophosphate. In another study, the $975 \mathrm{U} / \mathrm{L}$ plasma cholinesterase level was the cutoff value for indicating mechanical ventilation for $>7 \mathrm{~d}$ in 37 subjects. ${ }^{19}$ However, this study did not distinguish between organophosphate types, and plasma cholinesterase activity has wide variations across age, sex, disease, and drug administration. ${ }^{8}$

\section{RBC AChE at Weaning}

Because organophosphate poisoning causes muscle weakness, it may be critical to assess respiratory muscle strength before a weaning trial. In a patient with organophosphate poisoning, neuromuscular transmission was nor- 
Table 5. Comparison of Vital Signs and RBC AChE Activity at Weaning According to Weaning Outcome

\begin{tabular}{|c|c|c|c|}
\hline Variable & $\begin{array}{l}\text { Successful Weaning } \\
\quad(n=61)\end{array}$ & $\begin{array}{l}\text { Failed Weaning } \\
\qquad(n=9)\end{array}$ & $P$ \\
\hline $\mathrm{P}_{\mathrm{aO}_{2}} / \mathrm{F}_{\mathrm{IO}_{2}}$, mean $\pm \mathrm{SD}, \mathrm{mm} \mathrm{Hg}$ & $374.9 \pm 10.7$ & $330.6 \pm 20.2$ & .12 \\
\hline Breathing frequency, mean $\pm \mathrm{SD}$, breaths/min & $18.5 \pm 0.7$ & $18.3 \pm 1.8$ & .89 \\
\hline Glasgow coma scale, mean $\pm \mathrm{SD}$ & $14.8 \pm 0.1$ & $14.9 \pm 0.1$ & .74 \\
\hline Systolic blood pressure, mean $\pm \mathrm{SD}, \mathrm{mm} \mathrm{Hg}$ & $138.2 \pm 2.3$ & $135.2 \pm 6.7$ & .83 \\
\hline Amount of administered atropine until weaning trial, median (IQR), mg & $515.0(210.0-973.8)$ & $405.0(170.0-1,020.0)$ & .70 \\
\hline Amount of administered pralidoxime until weaning trial, median (IQR), $g$ & $53.3(37.0-74.0)$ & $49.0(30.5-79.5)$ & .28 \\
\hline $\mathrm{RBC}$ AChE at weaning, median (IQR), U/L & $3,538.0(1,368.0-8,924.0)$ & $2,902.0(1,892.0-3,611.0)$ & .34 \\
\hline Increased rate from admission to weaning trial, median (IQR), \% & $-17.9(-29.7-80.3)$ & $61.8(-81.6-300.8)$ & .86 \\
\hline
\end{tabular}

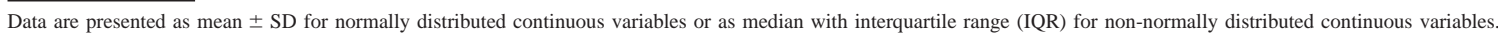
$\mathrm{RBC} \mathrm{AChE}=$ red blood cell acetylcholinesterase

Table 6. RBC AChE Activity at Weaning According to Weaning Outcome

\begin{tabular}{cccr}
\hline \hline $\begin{array}{c}\text { RBC AChE } \\
\text { Activity }\end{array}$ & $\begin{array}{c}\text { Successful Weaning } \\
(n=61)\end{array}$ & $\begin{array}{c}\text { Failed Weaning } \\
(n=9)\end{array}$ & $P$ \\
\hline$\leq 3,000 \mathrm{U} / \mathrm{L}, n(\%)$ & $25(41.0)$ & $5(55.6)$ & .48 \\
$\leq 1,000 \mathrm{U} / \mathrm{L}, n(\%)$ & $11(18.0)$ & $1(11.1)$ & $>.99$
\end{tabular}

The normal range of red blood cell acetylcholinesterase (RBC AChE) is 11,188-16,698 U/L.

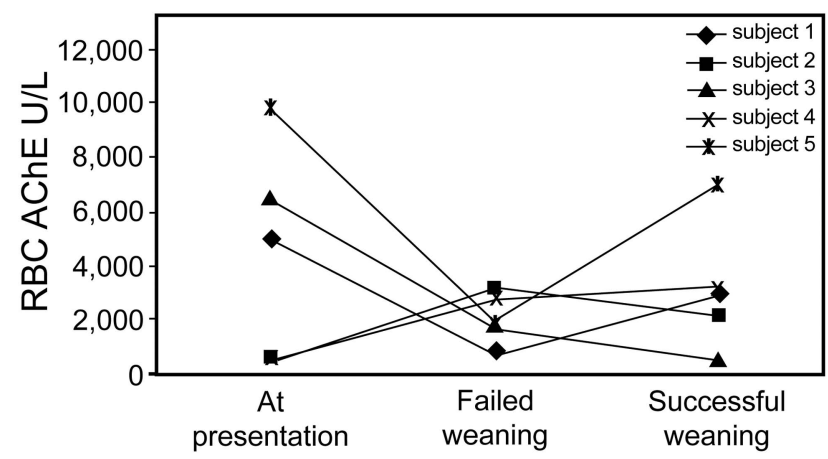

Fig. 2. Serial red blood cell acetylcholinesterase (RBC AChE) activities in 5 subjects at failed and successful weaning trials. Subject 1 ingested diethyl organophosphate, and subjects 2-4 ingested dimethyl organophosphate. Subject 5 was poisoned with unclassified organophosphate. All subjects had RBC AChE activity levels measured at presentation, at failed weaning, and following a successful weaning episode, but there were no significant differences in RBC AChE activity levels across time.

mal if the RBC AChE level was $>30 \%$ of normal, but an RBC AChE level of $<10 \%$ was associated with a strong impairment of neuromuscular transmission at $10-50-\mathrm{Hz}$ stimulation. ${ }^{8,16}$ Muscle AChE at $>30 \%$ of normal was associated with normal muscle force, and any decrease in the AChE level below this margin led to steeply reduced muscle force in a mouse phrenic nerve hemidiaphragm model at $50-\mathrm{Hz}$ stimulation. ${ }^{7}$ Patients with $\mathrm{RBC}$ AChE levels at $>40 \%$ of normal might be ready to be weaned from the ventilator. ${ }^{8}$

However, our study has revealed that RBC AChE activity was not associated with weaning outcomes. It was worth noting that $11(18.0 \%)$ of 61 successful weaning episodes were associated with $<1,000 \mathrm{U} / \mathrm{L}(\sim 10 \%$ of normal) RBC AChE in our study (Table 6). For these 11 subjects with $<1,000 \mathrm{U} / \mathrm{L} \mathrm{RBC} \mathrm{AChE}$ at weaning, the mean RBC AChE activity at admission was 3,108.4 \pm 1,105.5 U/L. Although not included in the study because of missing the admission RBC AChE assay, a 71-y-old male patient had been successfully weaned off the ventilator with an RBC AChE activity of $307 \mathrm{U} / \mathrm{L}$ after $13 \mathrm{~d}$ of hospitalization.

Lee and Tai ${ }^{22}$ suggested a threshold of RBC AChE at $7,500 \mathrm{U} / \mathrm{L}$ for successful weaning in a study of 17 subjects with organophosphate poisoning. The discrepancy between their findings and ours may be explained by the different weaning trial criteria used at the respective health-care institutions and by the different methods used in determining the cutoff value. In that study, the threshold was determined from RBC AChE activities measured every $2-3 \mathrm{~d}$ before extubation, whereas we used an absolute value of $\mathrm{RBC} \mathrm{AChE}$ at the weaning trial. In our experience, 41 $(67.2 \%)$ subjects had been successfully weaned and extubated with RBC AChE levels $<7,500 \mathrm{U} / \mathrm{L}$.

The lack of association between weaning outcome and $\mathrm{RBC} \mathrm{AChE}$ at weaning may be explained by different restoration rates between $\mathrm{RBC} \mathrm{AChE}$ and muscle $\mathrm{AChE}$. After a few days, completely aged RBC AChE loses the ability to reactivate, and replenishment of RBC AChE depends on de novo synthesis. Complete replacement of aged RBC AChE takes several months, whereas $50 \%$ of muscle $\mathrm{AChE}$ is regenerated within 1 week. ${ }^{23,24}$ With $\mathrm{AChE}$ inhibition, muscle necrosis, down-regulation or desensitization of the acetylcholine receptor, and oxidative stress together contribute to development of respiratory muscle weakness. ${ }^{25}$ These mechanisms may also lead to the fact 
that RBC AChE activity at weaning cannot reflect improvements in muscle force or predict the outcome of weaning.

In addition, we investigated whether other variables assessed at presentation, such as plasma cholinesterase, time interval from ingestion to presentation, and intent of ingestion, were associated with weaning outcome, but the results were insignificant (data not shown).

\section{Limitations}

(1) The sample size of this study was not sufficient to make strong conclusions. In particular, the number of subjects who had failed weaning trials and the subjects intoxicated with diethyl organophosphate were relatively low. A prospective study with a large number of subjects is needed to validate these findings. However, the wide variation of RBC AChE activity at weaning (453-12,716 U/L) and $18.0 \%$ of RBC AChE activity levels $<1,000 \mathrm{U} / \mathrm{L}$ in successful weaning episodes suggest that RBC AChE activity at weaning is not an indicator of weaning outcome.

(2) RBC AChE at weaning was checked within $12 \mathrm{~h}$ before or after weaning, and this was not a uniform time in subjects. More than $99 \%$ of RBC AChE aged within $1 \mathrm{~d}$ after dimethyl organophosphate ingestion and within $8 \mathrm{~d}$ after diethyl organophosphate ingestion based on the halflife data of aging. ${ }^{13,14}$ In our study, weaning was attempted at a mean of $11 \mathrm{~d}$ after organophosphate ingestion. Considering that the recovery of RBC AChE levels after aging is $1 \% / \mathrm{d}$ regardless of the chemical structure of organophosphate, the differences in RBC AChE levels within 12-h intervals from the weaning point might not be significant. ${ }^{15}$

(3) Ventilator-associated pneumonia may delay weaning despite the recovery of respiratory muscle function. The incidence of pneumonia in organophosphate-poisoned patients was reported to be as high as $58 \% .{ }^{26}$ In our study, pneumonia with a new radiographic infiltrate and inflammation signs occurred in $22(29.7 \%)$ of 74 subjects. Also, there were no significant differences in the incidence of pneumonia according to weaning outcome $(31.1 \%$ in successful weaning episodes vs $44.4 \%$ in failed weaning episodes, $P=.46$ ). If the 19 subjects with pneumonia were excluded, RBC AChE levels were $<1,000 \mathrm{U} / \mathrm{L}$ in $8(19.0 \%)$ of the remaining 42 successful weaning episodes, and the lowest activity of RBC AChE was $453 \mathrm{U} / \mathrm{L}$ in 42 successful weaning episodes without pneumonia. These findings were consistent with the result, including 19 subjects with pneumonia, that RBC AChE at $<10 \%$ of normal did not predict weaning failure.

(4) Among 80 subjects who underwent weaning trials in our hospital and did not satisfy the exclusion criteria, 64 were enrolled with an RBC AChE level assessed at weaning. This may have caused a selection bias, by which more severe clinical cases were enrolled for the study due to preferential RBC AChE assay on such patients expected to have a poor prognosis. However, there were no differences in potential factors related to clinical outcomes (such as hospitalization stay $[P=.62]$, ICU stay $[P=.99]$, and mechanical ventilation $[P=.91])$ and the amount of administered atropine $(P=.97)$ and pralidoxime $(P=.30)$ between 64 subjects with available RBC AChE activities at weaning and 16 subjects without available RBC AChE activities at weaning.

(5) Underlying heart dysfunctions or organophosphateinduced bronchorrhea, in addition to respiratory muscle dysfunction, might be responsible for unsuccessful weaning from mechanical ventilation and lead to the uselessness of RBC AChE activity for predicting weaning outcome. However, there was no re-infusion or increased amount of atropine to control bronchial secretion after failed weaning. Subjects who initially failed to be weaned from mechanical ventilation did not have a history of heart dysfunction and eventually successfully weaned. Again, regardless of the cause of failed weaning, successful weaning with lower RBC AChE activity levels still suggested an irrelevance of RBC AChE activity to weaning outcome.

(6) RBC AChE was associated with a need for mechanical ventilation or mortality after organophosphate poisoning. ${ }^{27}$ Because of the study design, patients who did not require mechanical ventilation or who had died before a weaning trial were not analyzed. Whether RBC AChE can predict a need for mechanical ventilation or mortality after organophosphate poisoning should be investigated in future studies with expanded inclusion criteria.

(7) Including repeated RBC AChE activities in one subject with $>2$ episodes of weaning can lead to significance from nonsignificant analysis. To exclude the error, we compared the values for RBC AChE activities during the first weaning episode in 64 subjects; 55 subjects experienced an episode of successful weaning, and 9 subjects experienced an episode of failed weaning. However, there was no difference in RBC AChE activities (3,311.0 $[12,97.0-8,924.0] \mathrm{U} / \mathrm{L}$ on successful weaning vs $2,902.0$ $[1,892.0-3,611.0] \mathrm{U} / \mathrm{L}$ on failed weaning, $P=.37$ ) and change in RBC AChE activities from admission to weaning $(-0.2[-0.27$ to +0.66$]$ on successful weaning vs $0.62[-0.76$ to +3.00$]$ on weaning failure, $P=.86$ ) between the 2 groups. Also, RBC AChE levels were $<1,000 \mathrm{U} / \mathrm{L}$ in $10(18.2 \%)$ of the 55 subjects who experienced successful weaning. In contrast, $44.4 \%$ of subjects had RBC AChE levels $>3,000 \mathrm{U} / \mathrm{L}$ in the failed weaning group. This statistical analysis also indicates that the RBC AChE level at the time of weaning may be meaningless. 


\section{RBC AChE After Organophosphate Poisoning}

\section{Conclusions}

RBC AChE activities within the first $24 \mathrm{~h}$ after dimethyl organophosphate poisoning may be useful in predicting the duration of mechanical ventilation; however, RBC $\mathrm{AChE}$ activities at the weaning trial may not help predict the outcome of weaning from mechanical ventilation in patients with organophosphate poisoning regardless of the chemical formulation of organophosphate.

\section{REFERENCES}

1. Dunn C, Bird SB, Gaspari R. Intralipid fat emulsion decreases respiratory failure in a rat model of parathion exposure. Acad Emerg Med 2012;19(5):504-509.

2. Shadnia S, Okazi A, Akhlaghi N, Sasanian G, Abdollahi M. Prognostic value of long QT interval in acute and severe organophosphate poisoning. J Med Toxicol 2009;5(4):196-199.

3. Jayawardane P, Senanayake N, Buckley NA, Dawson AH. Electrophysiological correlates of respiratory failure in acute organophosphate poisoning: evidence for differential roles of muscarinic and nicotinic stimulation. Clin Toxicol 2012;50(4):250-253.

4. Carey JL, Dunn C, Gaspari RJ. Central respiratory failure during acute organophosphate poisoning. Respir Physiol Neurobiol 2013; 189(2):403-410

5. Sungur M, Güven M. Intensive care management of organophosphate insecticide poisoning. Crit Care 2001;5(4):211-215.

6. Manu MS, Prashant V, Akila P, Suma MN, Basavanagowdappa H. A retrospective analysis of serial measurement of serum cholinesterase in acute poisoning with organophosphate compounds. Toxicol Int 2012;19(3):255-259.

7. Thiermann H, Eyer P, Worek F. Muscle force and acetylcholinesterase activity in mouse hemidiaphragms exposed to paraoxon and treated by oximes in vitro. Toxicology 2010;272(1-3):46-51.

8. Thiermann H, Zilker T, Eyer F, Felgenhauer N, Eyer P, Worek F. Monitoring of neuromuscular transmission in organophosphate pesticide-poisoned patients. Toxicol Lett 2009;191(2-3):297-304.

9. Herkert NM, Aurbek N, Eyer P, Thiermann H, Worek F. Comparative study of oxime-induced reactivation of erythrocyte and muscle AChE from different animal species following inhibition by sarin or paraoxon. Toxicol Lett 2010;194(3):94-101.

10. Herkert NM, Freude G, Kunz U, Thiermann H, Worek F. Comparative kinetics of organophosphates and oximes with erythrocyte, muscle and brain acetylcholinesterase. Toxicol Lett 2012;209(2): 173-178.

11. Rello J, Ollendorf DA, Oster G, Vera-Llonch M, Bellm L, Redman $\mathrm{R}$, et al. Epidemiology and outcomes of ventilator associated pneumonia in a large US database. Chest 2002;122(6):2115-2121.

12. de Souza LC, Guimarães FS, Lugon JR. Evaluation of a new index of mechanical ventilation weaning: the timed inspiratory effort. J Intensive Care Med 2013. doi: 10.1177/0885066613483265.

13. Eddleston M, Worek F, Eyer P, Thiermann H, Von Meyer L, Jeganathan $\mathrm{K}$, et al. Poisoning with the S-alkyl organophosphorus insecticides profenofos and prothiofos. QJM 2009;102(11):785-792.
14. Peter JV, Jerobin J, Nair A, Bennett A, Samuel P, Chrispal A, et al. Clinical profile and outcome of patients hospitalized with dimethyl and diethyl organophosphate poisoning. Clin Toxicol 2010;48(9): 916-923.

15. Eddleston M, Clark, RF. Insecticides; organic phosphorus compounds and carbamates. In: Nelson LS, Lewin NA, Howland MA, Hoffman RS, Goldfrank LR, Flomenbaum NE, editors. Goldfrank's toxicologic emergencies, 9th edition. New York: McGraw Hill; 2011:14501467.

16. Thiermann H, Szinicz L, Eyer P, Zilker T, Worek F. Correlation between red blood cell acetylcholinesterase activity and neuromuscular transmission in organophosphate poisoning. Chem Biol Interact 2005;157-158:345-347.

17. Moon JM, Chun BJ, Lee BK. Glasgow coma scale score in the prognosis of acute carbamate insecticide intoxication. Clin Toxicol 2012;50(9):832-837.

18. Li ZB, Gao XJ, Wang DH, Zhang B, Zhang ZP, Hu ZM, et al [Multicenter study of respiratory multiple index in predicting weaning from mechanical ventilation in patients with acute exacerbation of chronic obstructive pulmonary disease]. Zhonghua Wei Zhong Bing Ji Jiu Yi Xue 2013;25(6):339-342. Article in Chinese.

19. Manu MS, Prashant V, Akila P, Suma MN, Basavanagowdappa H. A retrospective analysis of serial measurement of serum cholinesterase in acute poisoning with organophosphate compounds. Toxicol Int 2012;19(3):255-259.

20. Brown CV, Daigle JB, Foulkrod KH, Brouillette B, Clark A, Czysz $\mathrm{C}$, et al. Risk factors associated with early reintubation in trauma patients: a prospective observational study. J Trauma 2011;71(1):3741.

21. Key PB, Fulton MH. Correlation between 96-h mortality and 24-h acetylcholinesterase inhibition in three grass shrimp larval life stages. Ecotoxicol Environ Saf 2006;63(3):389-392.

22. Lee P, Tai DY. Clinical features of patients with acute organophosphate poisoning requiring intensive care. Intensive Care Med 2001; 27(4):694-699.

23. Brank M, Zajc-Kreft K, Kreft S, Komel R, Grubić Z. Biogenesis of acetylcholinesterase is impaired, although its mRNA level remains normal, in the glucocorticoid-treated rat skeletal muscle. Eur J Biochem 1998;251(1-2):374-381.

24. Grubić Z, Sketelj J, Klinar B, Brzin M. Recovery of acetylcholinesterase in the diaphragm, brain, and plasma of the rat after irreversible inhibition by soman: a study of cytochemical localization and molecular forms of the enzyme in the motor end plate. J Neurochem 1981;37(4):909-916.

25. Abdollahi M, Karami-Mohajeri S. A comprehensive review on experimental and clinical findings in intermediate syndrome caused by organophosphate poisoning. Toxicol Appl Pharmacol 2012;258(3): 309-314.

26. Wang CY, Wu CL, Tsan YT, Hsu JY, Hung DZ, Wang CH. Early onset pneumonia in patients with cholinesterase inhibitor poisoning. Respirology 2010;15(6):961-968.

27. Brahmi N, Mokline A, Kouraichi N, Ghorbel H, Blel Y, Thabet H, et al. Prognostic value of human erythrocyte acetyl cholinesterase in acute organophosphate poisoning. Am J Emerg Med 2006;24(7): 822-827. 